\title{
Native Alien: Exotic Concrete House In The Tropics
}

NICHOLAS R. GELPI

Florida International University

This house seems to fit in with its surroundings naturally, blending in to the surrounding context mimicking the familiar forms around it. But a curious texture suggests something deeper is bubbling up from within. While the form of this house is native, echoed in the shapes of its neighbors, the material from which it is constructed is not from the region... well it didn't used to be anyway.

This house is constructed of an invasive species, clad with a system of tiles composed of exotic invasive species trees native to Australia, which have invaded the region and become a serious environmental problem. The combination of a local building type, with an exotic material, creates a hybrid identity, one which is native, but also alien.

Because this house project was both a renovation and extension, of an original 1962 home in Miami Beach, we wanted to respect the constructive method of the original structure, while blending the new with the old, blurring the boundary between the existing conditions and the addition.

A cladding system was developed utilizing non-native trees being removed from the Florida everglades. A proprietary process of harvesting invasive species trees, then chipping the trunks and mineralizing the woodchips was tested for its potential as a concrete aggregate. Research into this new material illustrated that the material was significantly more insulating than concrete, and $70 \%$ lighter. Additionally the carbon footprint of this house was significantly less when considering that no aggregate was mined, in addition to locking the carbon into the wood through the mineralization process.

The tiles are primarily located on the south façade, absorbing the most intense solar heat throughout the day, while also exhibiting a playful texture to activate its surface. A subtle wave pattern was developed based on arrangements of four unique tiles, each 24 " $\times 24$ " $\times 3$ ". Variations of the flat panels protruded one inch, two inch, and three inches to be 6 " at the thickest point.

A range of preliminary material studies illustrated varieties in texture and formula, as ingredients in the mixture are altered to produce differences in surface quality and porosity. The geometries range from convex to concave as the variety of shapes suggests the transformative nature of the materiality within each block.

The gentle wrapping of the existing house on the exterior produces a new environment on the interior, a softer quieter space more insulated from its surroundings, while acknowledging new ecological relationships. The ambition was to create a feedback whereby paradoxically we create a demand for the very material needing to be controlled if not eradicated; rooting a local craft based practice to disruptions of local ecology.

This combination of native and alien, suggests new hybrid relationships, both organic/ inorganic, new and old, and local and global. The goal is that this prototypical project is able to reorganize ecology but also building codes, practice and pedagogy as it spreads silently, not disrupting but distorting the various fields we occupy, in some cases for the better. 

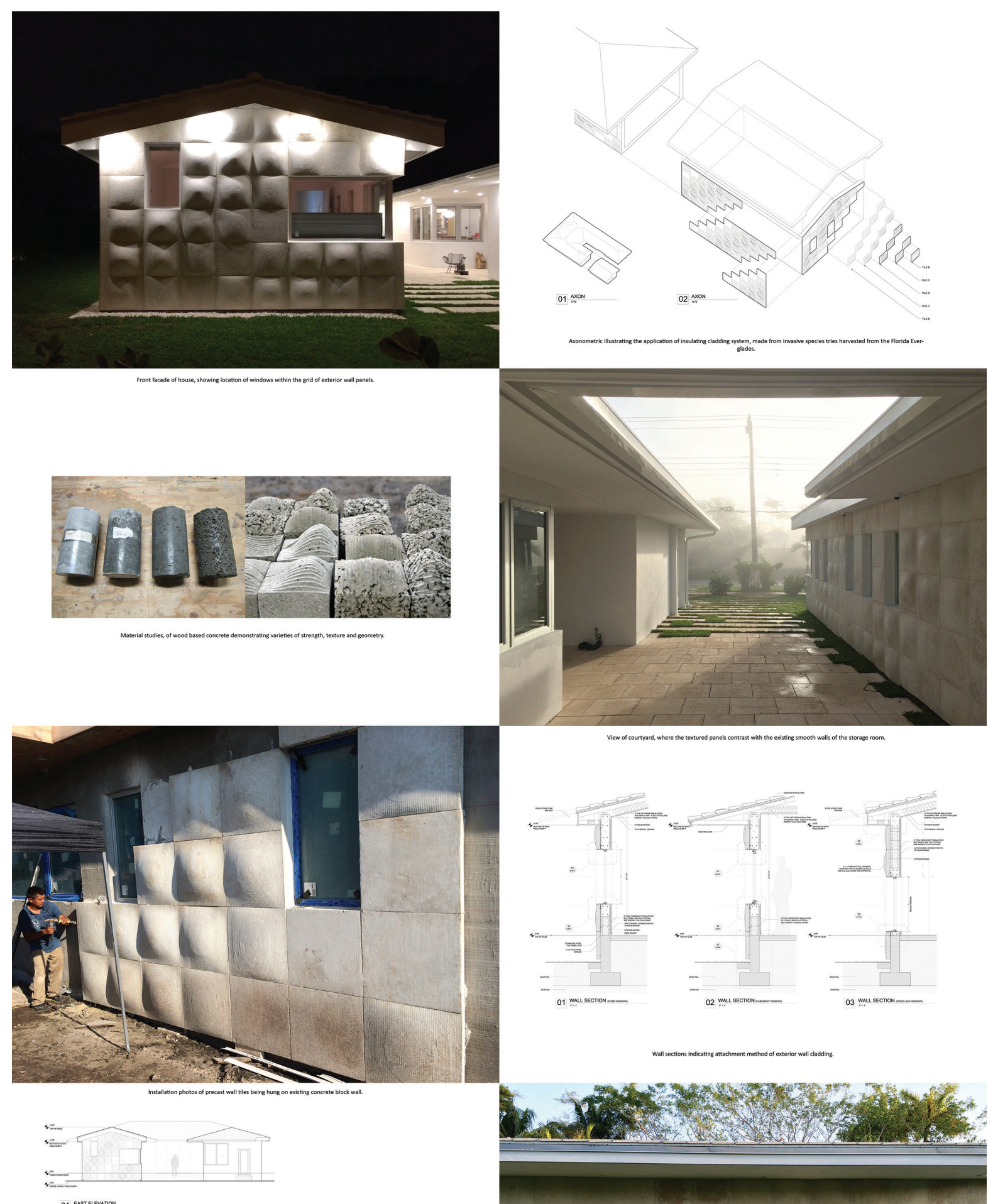

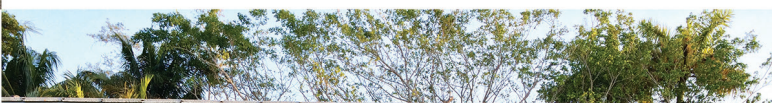
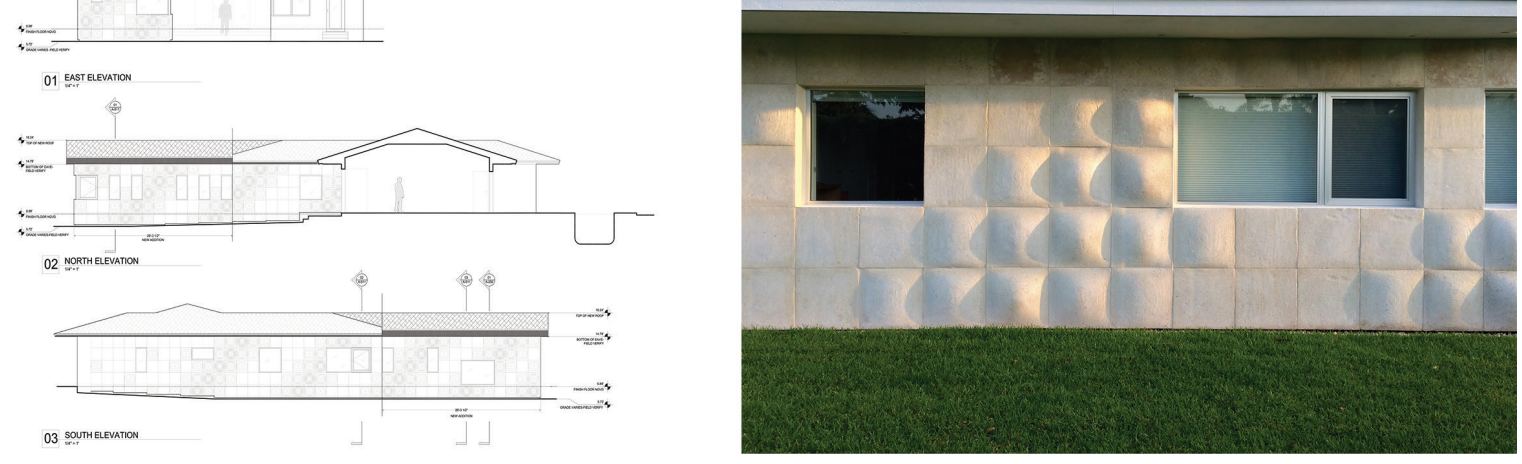